\title{
The Effect of Ageing on Selected Properties of Polylactide Modified with Blowing Agents
}

\author{
Karolina Głogowska', Łukasz Majewski", Tomasz Garbacz' , Aneta Tor-Świątek' \\ 1 Lublin University of Technology, Mechanical Engineering Faculty, Department of Technology and Polymer \\ Processing, ul. Nadbystrzycka 36, 20-618 Lublin, Poland \\ * Corresponding author's e-mail: I.majewski@pollub.pl
}

\begin{abstract}
The modification of processing and functional properties of polymeric materials is widely used in polymer processing. The current progress in this field involves the introduction of new ways of modifying polymers, often by changing their structure from homogeneous to porous. As a result, these polymers have lower density, and thus modified processing and functional properties. The paper presents the results of a study on the selected properties of the injection-molded specimens of polylactide (PLA) modified with blowing agents, before and after thermal ageing. Blowing agents with exothermic (Hydrocerol 530) and endothermic decomposition (Hydrocerol ITP-810, Expancel 951 MB 120 and LyCell F-017) were used. The mass content of the blowing agents was changed in the range from $0.5 \%$ to $3 \%$. The study involved examination of the changes in properties such as Young's modulus, tensile strength, tensile stress, strain at maximum tensile stress, Vicat softening temperature and impact strength depending on the mass content and type of blowing agent before and after the ageing process.
\end{abstract}

Keywords: injection molding, ageing of polymers, polylactide (PLA), biodegradable polymers, blowing agents,

\section{INTRODUCTION}

The ageing of polymeric materials is a complex and multifaceted phenomenon, and, due to its effects, it constitutes a particularly important engineering problem. The ageing process is defined in different ways by various authors. In general, ageing can be defined as the process of changes in the properties of a given material over time due to environmental factors of physical, chemical or biological nature. This phenomenon covers the whole of structural changes as well as the physical and chemical transformations occurring all over the material or only on its surface. In a vast majority of cases, ageing is negative and causes deterioration of certain material properties relative to their initial state, which may limit its applicability. While determining the suitability of a material for specific applications, it should be remembered that the ageing process may occur at all stages of product life, i.e. during product processing, transport, storage and even recycling, and not only during its operation [1-4].

Given the causes of ageing and their origin, this process can be divided into natural and artificial ageing, depending on the type of environment in which it occurs. Every material is sensitive to different environmental factors that induce ageing in broad terms. The factors leading to the ageing of polymeric materials include heat, moisture, electromagnetic radiation, radiation, oxygen and active chemical compounds [1,4-9].

As a result of ageing, the physical, mechanical and functional properties as well as its aesthetic features, durability and reliability of the material usually decrease. In a vast majority of cases, the induced changes are irreversible, because these transformations are based on the chemical changes occurring during degradation, polymerization, depolymerization, crosslinking and oxidation. The reversible changes mainly result from changes and physical phenomena occurring inside the 
material or on its surface. The examples of such phenomena are: fluid absorption, stress relaxation and crystallization [10-12].

The processes of structural changes in polymeric materials and the deterioration of their properties are usually long-lasting and are associated with the long-term exposure to adverse environmental factors. It is assumed that the visual effects of ageing for soft polymers occur after about three years, while for hard plastics - after five. Since the ageing processes are slow, this phenomenon is studied using the accelerated ageing methods. The effect of a given external factor on the ageing of a material can be determined by two cognitive algorithms. The first method enables the experimental determination of the degree of rate and kinetics of the changes in particular properties of the material. This method consists in determining an equation describing the ageing process as a function of a given property over time. As a result, it is later possible to determine how particular properties of the material change after a certain period of time. The other algorithm consists in the determination of the critical ageing times, i.e. the time after which a value of the analyzed property decreases below the previously established level used as a criterion of suitability of the tested part for further use. The ageing resistance can therefore be measured as a percentage loss of a given property after the elapse of a certain time unit. Once the critical ageing time has been reached, the part is usually no longer suitable for further use $[1,3,13,14]$.

Due to a complex nature of the ageing process, a considerable number of environmental factors affecting the material at the same time and the accompanying the physical changes and chemical reactions inside the material, any change in the composition of a material may alter the direction of changes occurring in this material, accelerate or slow them down. It is therefore justified to study the ageing process in the materials that have been chemically or physically modified by the addition of a filler and chemical modifiers into the matrix, especially when the products made of these materials are intended for longterm use, for example cables and wires. In certain engineering applications, modifications are used to make the material resistant to a specified external factor causing its accelerated degradation. The examples include UV stabilizers and heat stabilizers that significantly slow down the degradation of polymers resulting from the exposure to ultraviolet radiation or elevated temperature. The resistance to ageing can also be shaped by the modifications that have been used for other purposes than protection against environmental factors; this, however, changes the ability of a material to chemically interact with the environment. The examples of such modifiers include anti-blocking, antifogging and antimicrobial agents, plasticizers, antioxidants, blowing agents and compatibilizers. All agents and modifications that improve the functional properties of finished products made of polymers used in any way, for example, for producing active and intelligent packaging, may affect the course and kinetics of the ageing process of the materials [5, 10, 15-23].

The purpose of this study was to investigate the effect of the thermal aging on the selected thermal and mechanical properties of polylactide in a cellular extrusion process. For purposes of comparison, four different blowing agents were used, each of them characterized by a different mechanics of pore formation in the polymer matrix. In order to better understand the effect of the employed blowing agents on the ageing process, the investigation of the mechanical and thermal properties was carried out for different mass contents of the active blowing agent.

\section{METHODS}

\section{Materials}

The experiments of a cellular injection molding process were performed on biodegradable polylactide (PLA), Ingeo Biopolymer 2002D, manufactured by Nature Works LLC (Minneton$\mathrm{ka}$, USA). Basic technical data of the material provided by the manufacturer are listed in Table 1 . The material can be processed by conventional injection; however, due to its hygroscopic properties, it should be dried before processing.

PLA was modified by four different blowing agents: Expancel $951 \mathrm{MB}$ 120, Hydrocerol 530, Hydrocerol ITP-810 and LyCell F-017.

Expancel 951 MB 120, manufactured by Akzo Nobel (Sulzbach, Germany), has the form of small spherical particles containing hydrocarbon as active substance, in the amount of $65 \%$. The coating of microspheres is made of ethylenevinyl acetate (EVA) copolymer. As a result of heating, the thermoplastic microsphere undergoes plasticizing, and the increasing gas pressure 
Table 1. Ingeo Biopolymer 2002D technical data provided by manufacturer

\begin{tabular}{|l|c|c|}
\hline \multicolumn{1}{|c|}{ Property } & Unit & Value \\
\hline Specific Gravity $\left(190^{\circ} \mathrm{C} ; 2.16 \mathrm{~kg}\right)$ & $\mathrm{kg} / \mathrm{m}^{3}$ & 1240 \\
Mass Flow Rate & $\mathrm{g} / 10 \mathrm{~min}$ & $5-7$ \\
Tensile Strength & $\mathrm{MPa}$ & 69 \\
Strain at maximum tensile stress & $\%$ & 6 \\
Young's modulus & $\mathrm{MPa}$ & 2500 \\
Notched Izod Impact & $\mathrm{J} / \mathrm{m}^{2}$ & 0.24 \\
\hline
\end{tabular}

inside the sphere leads to an increase in its size, up to $120 \mu \mathrm{m}$. After increasing its volume, the gas remains inside the sphere. Expancel 951 MB 120 is therefore a physical blowing agent that uses the mechanism of hydrocarbon volume change to form pores [24, 25].

Hydrocerol 530 is a granulated blowing agent manufactured by Claser (Muttenz, Switzerland). The active ingredient responsible for the formation of pores is azodicarbonamide, which undergoes exothermic decomposition at above $200^{\circ} \mathrm{C}$ and at the same time releases several gaseous components, $\mathrm{N}_{2}, \mathrm{CO}, \mathrm{CO}_{2}$ and $\mathrm{NH}_{3}$. However, in polymer processing, modified azodicarbonamide is used, enriched with substances that accelerate decomposition and lower the breakdown point to $170^{\circ} \mathrm{C}$. The active substance content in the granulate product ranges from 47.5 to $51.5 \%[26,27]$.

Hydrocerol ITP 810 is a granulated blowing agent manufactured by Clariant (Muttenz, Switzerland). The content of active substance in the granulate is $50 \%$. Like other blowing agents of the Hydrocerol type, ITP contains a mixture of active substances consisting of sodium bicarbonate and 2-hydroxypropane-tricarboxylic acid (citric acid). The thermal breakdown of sodium hydrogencarbonate starts already above $50^{\circ} \mathrm{C}$, but it proceeds slowly, and increasing the temperature significantly accelerates the kinetics of decomposition of this compound into calcium carbonate, carbon dioxide and water. In polymer processing, it is assumed that sodium bicarbonate leads to effective foaming above $140^{\circ} \mathrm{C}$. Citric acid remains stable up to $150^{\circ} \mathrm{C}$, and starts to melt and break down only above $175^{\circ} \mathrm{C}$. The decomposition occurs in two stages, first by dehydration to trans-aconitic anhydride and then by decarboxylation to itaconic or citraconic anhydride, the by-product of which is $\mathrm{CO}_{2}$ responsible for pore formation. According to the manufacturer's data, an increase in the citric acid content leads to an elevation in the temperature of effective foaming, while an increase in the content of sodium bicarbonate decreases this temperature [26, 28, 29].

LyCell F-017 is a granulated blowing agent manufactured by Ly-Tec (Ingelheim, Germany). Like the previous blowing agent, it is a mixture of active substances containing sodium bicarbonate and citric acid, so the by-products of its thermal decomposition process are: water and $\mathrm{CO}_{2}$. The total content of active substances in the granulate is $70 \%$, and according to the manufacturer's technical specifications its breakdown point occurs at $155^{\circ} \mathrm{C}$. This temperature is lower than that for Hydrocerol ITP 810, which may point to the dominance of sodium bicarbonate in the mixture $[26,28,29]$.

In the tests, the blowing agents were added to the polymer in the weight in weight concentration of $0.5 \%, 1.5 \%$ and $3 \%$ (relative to the matrix), and mechanically mixed. When calculating the mass content of individual blowing agents, the content of active substance in the granulated product, and not the mass of the granulated product itself was taken into account. The processing temperature was set in the range of 160 to $185^{\circ} \mathrm{C}$ to ensure good efficiency of the process for the selected blowing agents, following the rule that the breakdown point of the blowing agent must be higher than the plasticizing temperature of the material but lower than its melting point.

Table 2. Characteristics of blowing agents used in the investigated process

\begin{tabular}{|c|c|c|c|c|}
\hline Commercial name & Expancel $951 \mathrm{MB} 120$ & Hydrocerol 530 & Hydrocerol ITP-810 & LyCell F-017 \\
\hline $\begin{array}{l}\text { Dose, } \% \\
\text { Active Substance, } \% \\
\text { Decomposition } \\
\text { Breakdown Point, }{ }^{\circ} \mathrm{C} \\
\text { Processing Temperature, }{ }^{\circ} \mathrm{C}\end{array}$ & $\begin{array}{c}0.5-3 \\
65 \\
\text { Endothermic } \\
140 \\
140-190\end{array}$ & $\begin{array}{c}0.5-3 \\
50 \\
\text { Exothermic } \\
170 \\
170-190\end{array}$ & $\begin{array}{c}0.5-3 \\
50 \\
\text { Endothermic } \\
160 \\
160-180\end{array}$ & $\begin{array}{c}0.5-3 \\
70 \\
\text { Endothermic } \\
155 \\
170-210\end{array}$ \\
\hline
\end{tabular}




\section{Experimental test stands}

The test specimens were produced using Arburg's injection molding machine, Allrounder $320 \mathrm{C}$, with a twin mold cavity. The machine is used for producing the samples in the shape of dumbbells. The mold cavity had a flow system with cold channels.

The temperature of the plasticizing zones was set as follows: zone $1-160^{\circ} \mathrm{C}$, zone $2-170^{\circ} \mathrm{C}$, zone $3-180^{\circ} \mathrm{C}$, zone $4-185^{\circ} \mathrm{C}$. The total time of the process was set to $34-35 \mathrm{~s}$, the cooling time of a molded piece was $25 \mathrm{~s}$, and the injection and clamp times were set equal to $2 \mathrm{~s}$.

The obtained injection molded parts were subjected to the following tests before and after thermal ageing: static tensile tests, impact strength tests and Vicat softening temperature tests. The static tensile tests of mechanical properties were conducted on the Zwick Roel Z010 testing machine in accordance with the PN-EN ISO 527-1: 1998 standard. The test parameters were as follows: initial force $-0.1 \mathrm{MPa}$, tensile modulus speed $-1 \mathrm{~mm} / \mathrm{min}$, test speed was $50 \mathrm{~mm} / \mathrm{min}$. At least 10 measurements were performed for each batch of specimens.

The impact tests were carried out using a Charpy hammer. The hammer has an initial energy of $5 \mathrm{~J}$, at the standstill it is raised and blocked to form a $150^{\circ}$ angle to the vertical. The tests were carried out in accordance with ISO 179-1: 2010.

The Instron Ceast HV3 HDT \& Vicat testers equipped with three workstations were used for thermal tests. These testers are used to determine the temperature at which the specimens undergo deformation under the specified load conditions. The tests are run at a heating rate of the oil bath set equal up to $300^{\circ} \mathrm{C}$. The test chamber is divided into two parts: a temperature bath in the central part of the chamber and a platform with test stations. Each workstation is equipped with a universal set of weights enabling all load combinations in HDT and VICAT tests. The Vicat softening temperature test was performed in compliance with the PN-EN ISO 306: 2014-02.

The laboratory tests of accelerated ageing were carried out in a heat chamber with a temperature range from 0 to $300^{\circ} \mathrm{C}$. According to the ASTM F1980- 07 (2011), the ageing temperature in the heat chamber was set equal to $60^{\circ} \mathrm{C}$ [25]. The $\mathrm{Q}_{10}$ was assumed to have a value of 2 , because this value is widely used to calculate the ageing factor (based on the Arrhenius equations).
More aggressive coefficients can be applied if a system under study has been sufficiently well described in the specialist literature. On the basis of the plot shown in Fig. 2, specimens in the form of injection molded parts were left to degrade for 4 weeks at $60^{\circ} \mathrm{C}$, which corresponds to degradation at room temperature for one year.

\section{RESULTS AND DISCUSSION}

Figures. 1-5 compare the properties of the modified PLA obtained in static tensile, impact strength and Vicat tests, before and after ageing. The range of changes is plotted versus the blowing agent type and its active substance content expressed in percentage by mass.

Figure 1a shows the changes in Young's modulus of modified PLA as a function of the blowing agent content and type. All the curves in the plot show a decreasing trend - the higher the blowing agent content, the lower the Young's modulus; however, in no case does the decrease exceed $3000 \mathrm{MPa}$. The lowest Young's modulus is shown by the specimens containing the blowing agents based on sodium bicarbonate and citric acid. The addition of 3\% wt. LyCell to PLA leads to a decrease in Young's modulus by $8.7 \%$; the same is observed for Hydrocerol ITP 810 - Young's modulus decreases by $9 \%$. The curve illustrating the changes in the PLA modified with Expancel 951 MB 120 is definitely smoother, and the difference between individual blowing agent contents becomes smaller and smaller, and between 1.5\% and $3 \%$ by mass contents the difference is only $20 \mathrm{MPa}$. A general change in Young's modulus for the 3\% content of this blowing agent is 3.9\%. The smoothest curve was obtained for the PLA modified with Hydrocerol 530. This may be related to the exothermic character related to the decomposition of this blowing agent. Despite the smooth curve, Young's modulus for the 3\% wt. of the blowing agent is $3150 \mathrm{MPa}$, which means it is $5.2 \%$ lower than for pure PLA and $30 \mathrm{MPa}$ lower than for the PLA modified with Expancel.

Figure $1 \mathrm{~b}$ shows the plots of Young's modulus of the PLA modified with different blowing agents, after thermal ageing. Young's modulus of pure PLA decreases from $3320 \mathrm{MPa}$ to 2437 $\mathrm{MPa}$, compared to its value before ageing. This parameter is higher for all other PLA specimens containing blowing agents after ageing. It can therefore be claimed that the presence of the 
a)

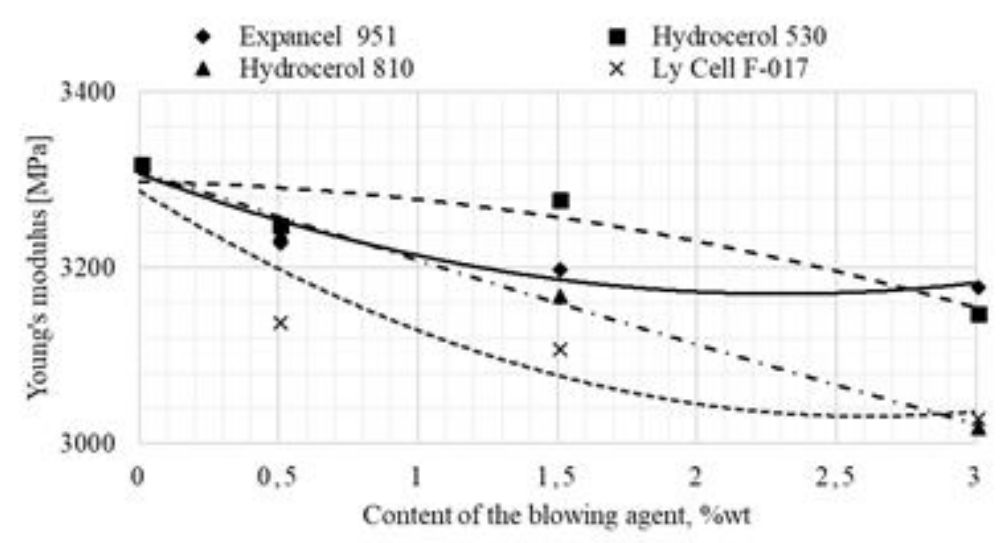

b)

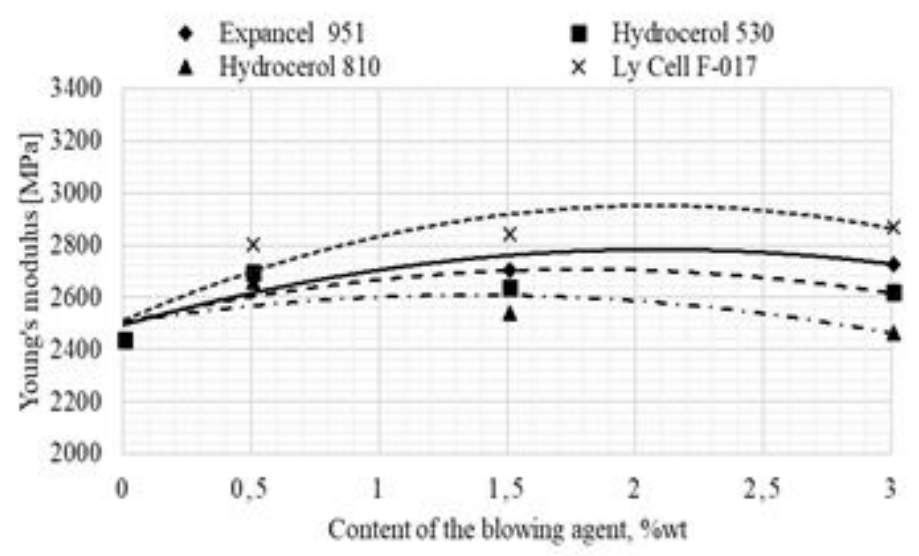

Figure 1. Plots of Young's modulus of modified PLA before (a) and after (b) ageing versus blowing agent type and content

blowing agents reduces the negative effect of thermal ageing on Young's modulus. As for Hydrocerol ITP 810, the highest Young's modulus is obtained for the specimens containing $0.5 \%$ wt. and amounts to $2670 \mathrm{MPa}$, which is $12.8 \%$ higher than that of pure PLA. On increasing its contents, Young's modulus decreases to 2473 MPa for 3\% wt., which is $18.1 \%$ lower than before ageing. Despite a similar composition of LyCell to Hydrocerol ITP 810, the PLA specimens containing this blowing agent have a significantly higher Young's modulus after ageing, which increases with increasing the blowing agent content up to $2876 \mathrm{MPa}$ for $3 \% \mathrm{wt}$. content of the active substance, which gives a 5\% decrease, compared to the same content before ageing. Despite the similar composition of LyCell and Hydrocerol ITP 810, the PLA modified with these blowing agents has significantly different values of Young's modulus after ageing. This may be due to various sodium bicarbonate and citric acid ratios or different active substance contents, as a result of which different amounts of the matrix with the blowing agent are introduced into the mixture. Similarly, to the above-mentioned case, the PLA containing Hydrocerol 530 achieves the highest Young's modulus for $0.5 \%$ wt., amounting to $2703 \mathrm{MPa}$. A further increase in its content leads to a decrease in Young's modulus after ageing to $2627 \mathrm{MPa}$ for 3\% wt. of the blowing agent, which means it is $16.6 \%$ lower than before ageing. The specimens of PLA modified with Expancel 951 MB 120 show an increase in Young's modulus after ageing with increasing the blowing agent content, amounting to $2736 \mathrm{MPa}$ at $3 \%$ wt., which is $17.4 \%$ lower than before ageing. The results obtained for the specimens containing this blowing agent also differ the least from the obtained curve, before and after ageing alike. This may be related to the physical nature of pore formation, a lack of chemical reactions and the formation of by-products. 
Fig. 2a shows the curves illustrating the variations in the tensile strength of PLA depending on the blowing agent content and type. It can be observed that the tensile strength of specimens decreases with the increasing blowing agent content, irrespective of the blowing agent type. This is natural due to a change in the cross-section of the specimen caused by cellular injection molding. Nevertheless, it has been observed that tensile strength depends on the blowing agent type. The highest tensile strengths were obtained with blowing agents containing sodium bicarbonate and citric acid. The tensile strength of PLA containing 3\% wt. LyCell is equal to $60.8 \mathrm{MPa}$, so it is $16.3 \%$ lower compared to the tensile strength of pure PLA that amounts to $72.7 \mathrm{MPa}$. The tensile strength of PLA modified with the highest tested content of Hydrocerol ITP 810 is slightly lower than that obtained for the PLA specimens containing LyCell and is equal to $59 \mathrm{MPa}$. The observed small differences in tensile strength for these two blowing agents most probably result from the differences in the ratio of active substances. The tensile strength of PLA modified with 3\% wt. Hydrocerol 530 is significantly lower than that obtained for the two previous blowing agents, amounting to $50.6 \mathrm{MPa}$, which means it is $33.4 \%$ lower than the tensile strength of pure PLA. The specimens of PLA modified with Expancel 951 MB 120 have the lowest tensile strength for all tested blowing agents. For 3\% wt., the tensile strength is equal to $48.1 \mathrm{MPa}$, which is $33.8 \%$ lower than for the unmodified PLA. This may be related to the nature of pore formation when the volume of EVA microspheres filled with hydrocarbon increases. The microspheres do not break during pore formation and may later become the area of crack initiation in tensile tests.

Fig. $2 b$ shows the changes in the tensile strength of modified PLA after thermal ageing. The mean tensile strength of the unmodified PLA after ageing is only $1.5 \%$ lower than that before ageing. The ageing process leads to a decrease in the tensile strength of the PLA modified with all contents of all tested blowing agents, except Hydrocerol 530, where the decrease in tensile

a)

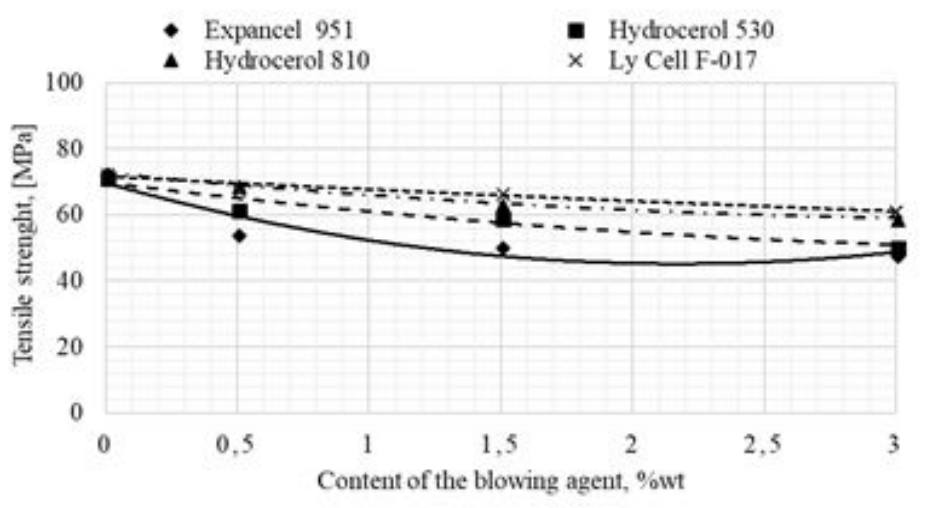

b)

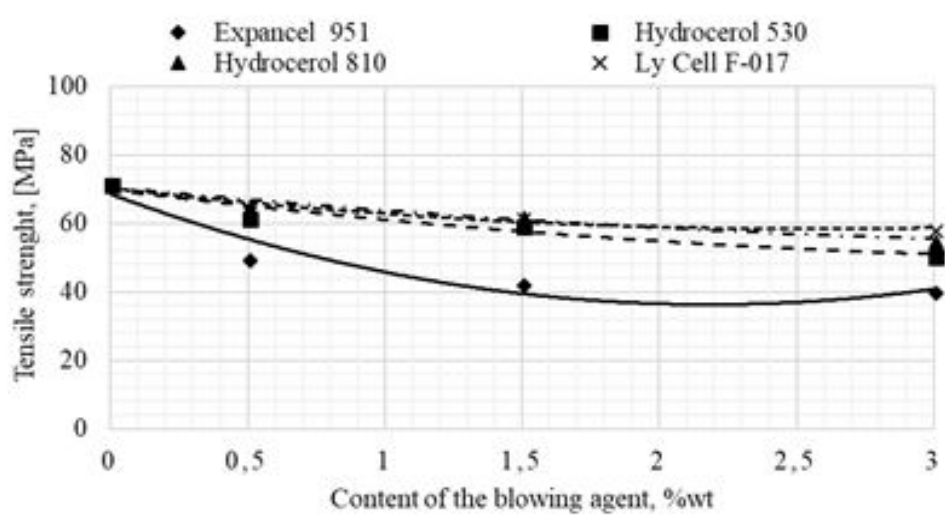

Figure 2. Plots of tensile strength of modified PLA before (a) and after (b) ageing versus blowing agent type and content 
strength is negligible. This may be due to the exothermic nature of the active substance decomposition and the release of other gases than in the case of LyCell and Hydrocerol ITP 810. It has been observed that the decrease in the strength of these two blowing agents is the lower, the higher the content of active substance becomes. For example, the tensile strength of the PLA containing $0.5 \%$ wt. LyCell is $4 \mathrm{MPa}$ lower after ageing than that before ageing, while for 3\% wt. LyCell the difference amounts to $2 \mathrm{MPa}$. The specimens of PLA modified with Hydrocerol ITP 810 show a similar trend, and the differences in tensile strength are 4.1 $\mathrm{MPa}$ and $3.7 \mathrm{MPa}$, respectively. The ageing process significantly affects the tensile strength of the PLA modified with Expancel $951 \mathrm{MB} 120$. For the smallest tested content, the difference between the tensile strengths before and after ageing is $3.5 \mathrm{MPa}$, while for the highest blowing agent content, it is $8 \mathrm{MPa}$. What is more, the tensile strength after ageing for 3\% wt. Expancel $951 \mathrm{MB} 120$ is equal to $40.1 \mathrm{MPa}$, which is as much as $44 \%$ lower than that obtained for the unmodified PLA.

The results of the maximum tensile stress of the modified PLA before and after thermal ageing versus the blowing agent type and content are shown in Figs. 3a and 3b. The plots demonstrate that the ageing process affects unfilled polylactide, and the obtained mean value of maximum tensile stress is higher after ageing than before it by $24.61 \%$. The addition of Expancel 951, Hydrocerol 530, Hydrocerol ITP 810 and LyCell to PLA results in an increase in the maximum tensile stress in the entire tested range of the blowing agent contents after the ageing process. The lowest increase in the maximum tensile stress after the ageing process was observed for the specimens containing LyCell. The addition of $0.5 \%$ and $1.5 \%$ wt. of this blowing agent results in a $13.03 \%$ increase in the tested parameter. The plot shows that the addition of $1.5 \% \mathrm{wt}$. Expancel 951 leads to an increase in strain at the highest tensile stress by $48.68 \%$ compared to the

a)

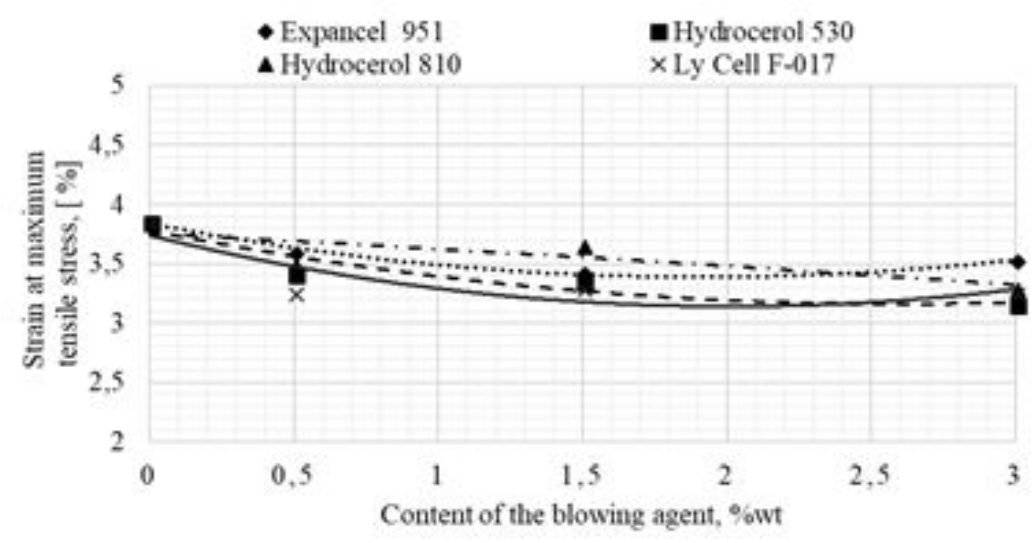

b)

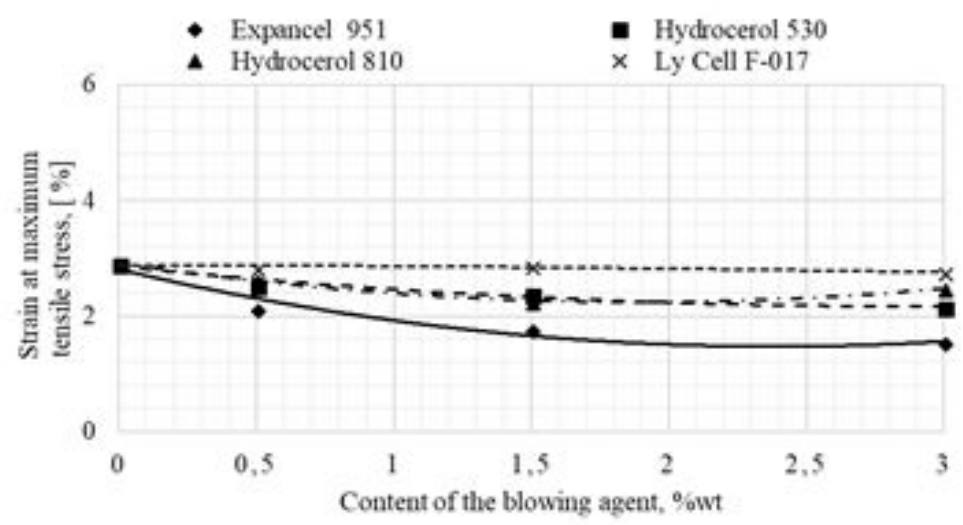

Figure 3. Plots of strain at maximum tensile stress of modified PLA before (a) and after (b) ageing versus blowing agent type and content 
results of the tests carried out before ageing. The changes observed for the analyzed mixtures depend on the presence of a blowing agent, its type and mass content.

The results of the Charpy impact tests are plotted in Figures $4 \mathrm{a}$ and $4 \mathrm{~b}$ as the relationship between impact strength and the content of the tested blowing agents before and after thermal ageing. After ageing, the impact strength of the specimens increases considerably. For the entire range of tested blowing agent contents, the highest increase in the impact strength was observed for 3\% wt. Hydrocerol 810, while the lowest increase - for $0.5 \%$ wt. LyCell. When compared to the results obtained for individual blowing agents before and after thermal ageing they were $471.88 \%$ and $54.62 \%$, respectively.

Figures $5 \mathrm{a}$ and $5 \mathrm{~b}$ show the relationship between the Vicat softening temperature and the blowing agent type and content, before and after ageing. The addition of blowing agents leads to a slight decrease in the softening temperature in the entire tested range of blowing agent contents when compared to a solid polymeric material before the ageing process. As regards the effect of the tested blowing agents, the lowest softening temperature can be observed for the specimens of PLA modified with $3 \%$ wt. Hydrocerol 530. The VST is $61.67^{\circ} \mathrm{C}$, which corresponds to a $2.72 \%$ decrease in the initial value. The smallest difference in the entire range of the tested blowing agent was observed for the specimens of PLA modified with Hydrocerol 810, where the VST decreased from $63.40^{\circ} \mathrm{C}$ (PLA) to $63.27^{\circ} \mathrm{C}$ for the lowest tested blowing agent content, i.e. by $0.20 \%$. However, the observed differences are small (up to $2.72 \%$ ) and are in the margin of error; therefore, it can be claimed that neither the blowing agent type nor its addition in the tested contents, significantly affect the Vicat softening temperature.

While analyzing the softening temperatures of the specimens after ageing, one can observe that this parameter increases regardless of the applied type of blowing agent. The highest increase

a)

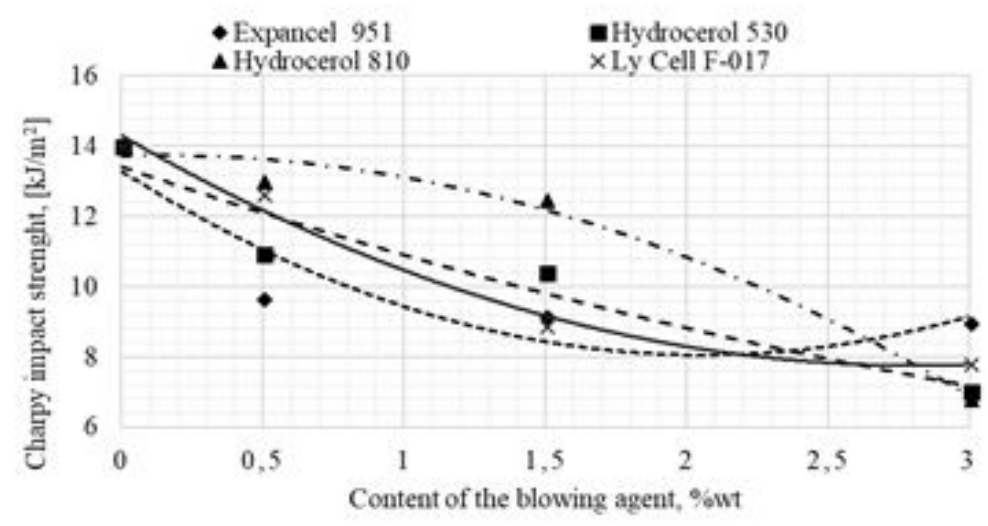

b)

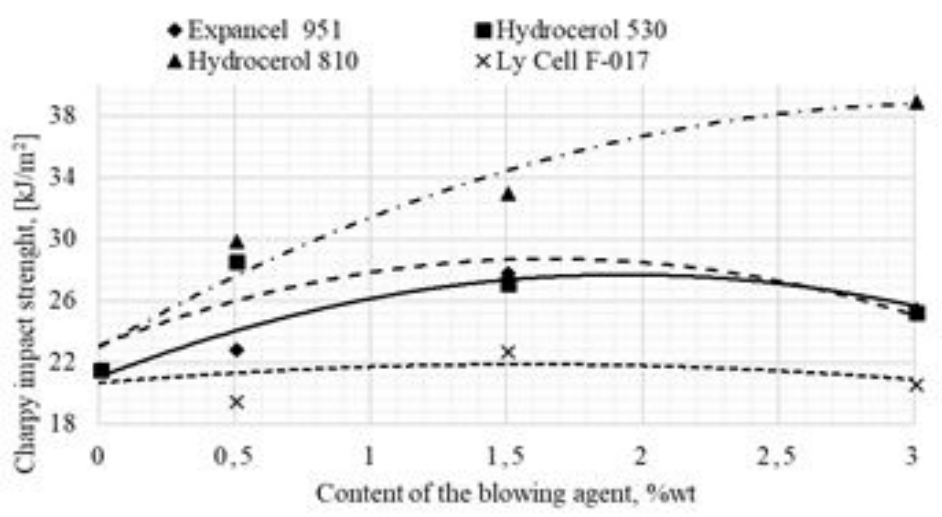

Figure 4. Plots of Charpy impact strength of modified PLA before (a) and after (b) ageing versus blowing agent type and content 
a)

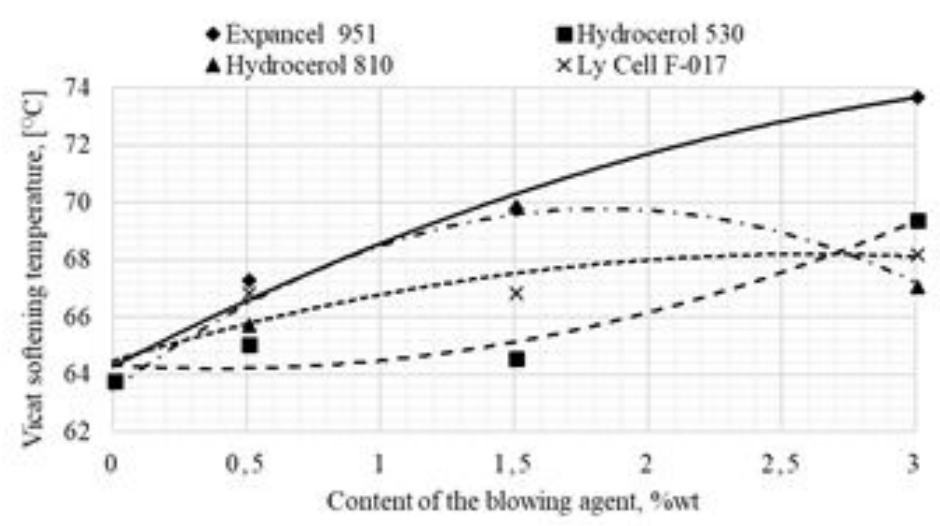

b)

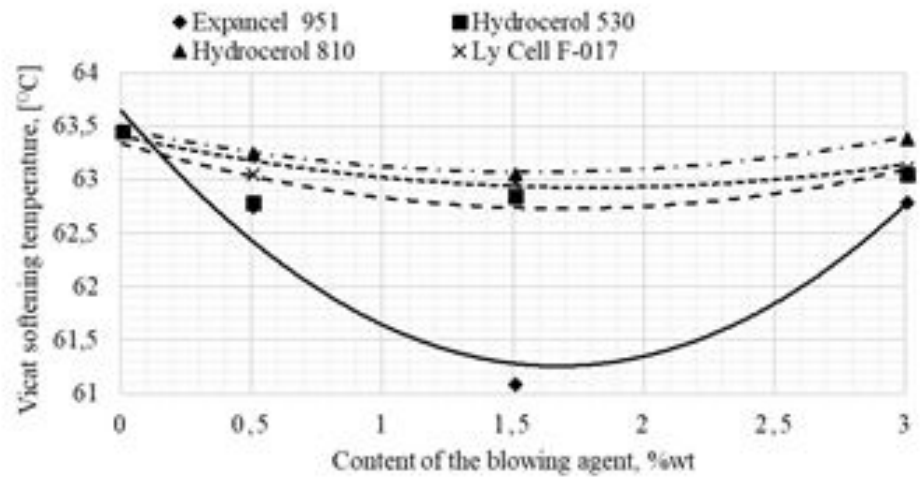

Figure 5. Plots of Vicat softening temperature of modified PLA before (a) and after (b) ageing versus blowing agent type and content

in the temperature amounting to $14.85 \%$ was obtained for 3\% wt. Expancel 951, which corresponds to an increase by $10.95^{\circ} \mathrm{C}$ compared to the temperature of the specimen before ageing. The lowest increase in the softening temperature was observed for the unmodified PLA, which corresponds to a $0.59 \%$ increase compared to that of the specimen prior to ageing. While analyzing the plots, one can observe that the thermal ageing process has a significant effect on the softening temperature of polylactide modified with the blowing agents.

\section{CONCLUSION}

The investigation of the ageing process and mechanisms governing this phenomenon and of the possibility of predicting the changes in the properties of polymeric materials is very important in terms of the processability of these materials and safe use of polymeric products. On the one hand, constructional plastics are required to retain their functional properties (primarily strength endurance) in a specified range value for as long as possible, regardless of the environment and conditions under which they are used, and on the other - in accordance with environmental protection trends - the everyday objects made of polymeric materials should be recyclable, or even (depending on the type of application) biodegradable. The knowledge on both mechanisms of the ageing processes and factors affecting these processes is necessary to ensure the correct and safe use of obtained products under specific conditions in a given period.

\section{Acknowledgements}

The study is part of a Polish-Czech research project, "Novel Processing Techniques of Biodegradable Polymers for Biomedical Applications" (No. 7AMB16PL070). 


\section{REFERENCES}

1. Jachowicz T., Sikora R.: Methods of forecasting of the changes of polymeric products properties. Polimery, 3(51), 2006, 177-185.

2. Cangialosi D., Boucher V.M., Colmeneroabc J.: Physical aging in polymers and polymer nano composites: recent results and open questions. Soft Matter, 9, 2013, 8619-8630.

3. Lewis P.R.: Forensic polymer engineering: why polymer products fail in service. Woodhead/CRC Press, 2016.

4. Ghosh S., Khastgir D., Bhowmick A.: Thermal degradation and aging of segmented polyamides. Polymer Degradation and Stability, 3(67), 2000, 427-436.

5. Kaynak C., Sari B.: Accelerated weathering performance of polylactide and its montmorillonite nanocomposite. Applied Clay Science, 121-122, 2016, 86-94.

6. Monnier X., Saiter A., Dargent E.: Physical aging in PLA through standard DSC and fast scanning calorimetry investigations. Thermochimica Acta, 648, 2017, 13-22.

7. Celina M., Gillen K.T., Assink R.A.: Accelerated aging and lifetime prediction: review of non-Arrhenius behavior due to two competing processes. Polymer Degradation and Stability, 90(3), 2005, 395-404.

8. Hu Y., Lang, A. W., Li X., Nutt S.R.: Hygrothermal aging effects on fatigue of glass/polydicyclopentadiene composites. Polymer Degradation and Stability, 110, 2014, 464-472.

9. Tor-Świątek A., Sikora J.: Effect of poly (vinyl chloride) modification with microspheres on geometric structure of extrudates. Przemysł Chemiczny, 92(4), 538-541

10. Jia Z., Tan J., Han C., Yang Y., Dong L.: Poly (ethylene glycol-co-propylene glycol) as macromolecular plasticizing agent for polylactide: thermomechanical properties and aging. Journal of Polymer Science, 114, 2, 2009, 1105-1117.

11. Miertus S., Ren, X.: Environmetally degradable plastics and waste management. Polimery, 7-8(47), 2002, 545-550.

12. Chiellini E., Cinelli, P., D’Antone, S., Ilieva, V. I.: Environmentally degradable polymeric materials (EDPM) in agricultural applications - an overview. Polimery, 7-8(47), 2002, 538-544.

13. Tor-Swiatek A.; Suberlyak D., Krasins'kyi B. \& et al.: Distribution and Geometric Characteristics of Pores and the Strength Properties of Extrudates Obtained by the Twin-Screw Extrusion. Materials Science Volume, 49(6), 812-818.

14. Brzozowska-Stanuch A., Rabiej S., Stanuch, W.: The influence of accelerated weathering conditions - UV radiation and temperature on polyamides and polypropylene. Technical Transactions, 3(106), 2009, 43-49.
15. Xanthos M.: Functional fillers for plastics. WileyVCH Verlag GmbH \& Co. KGaA, Weinhaim, 2010.

16. Pospisil J., Horak Z., Krulis Z., Nespurek S., Kuroda $S$.: Degradation and aging of polymer blends I. Thermomechanical and thermal degradation. Polymer Degradation and Stability, 65(3), 1999, 405-414.

17. Głogowska K., Sikora J., Duleba B.: Effect of mechanical properties of metal powder-filled hybrid moulded products. Journal of Polymer Engineering, 7(36), 2016, 705-712.

18. Ito M., Nagai, K.: Degradation issues of polymer materials used in railway field. Polymer Degradation and Stability, 10(93), 2008, 1723-1735.

19. Ito M., Inayoshi, S., Moriyama, K.: A simple method for evaluation of heat resistant property of elastomers. Polymer Degradation and Stability, 10(93), 2008, 1935-1938.

20. Boubakri A., Haddar N., Elleuch K., Bienvenu Y.: Impact of aging conditions on mechanical properties of thermoplastic polyurethane. Materials \& Design, 31(9), 2010, 4194-4201.

21. Ito M., Nagai K.: Analysis of degradation mechanism of plasticized PVC under artificial aging conditions. Polymer Degradation and Stability, 92(2), 2007, 260-270.

22. Garbacz T.: Structure and properties of cellular thin-walled cable coatings. Polimery, 11-12(57), 2012, 91-94.

23. Garbacz T., Jachowicz T., Gajdos I., Kijewski G.: Research on the influence of blowing agent on selected properties of extruded cellular products. Advances in Science and Technology, 9(28), 2015, 81-88.

24. Product specification for Expancel ${ }^{\circledR}$ Microspheres, Expancel MB. Issue 2017.11. www.expancel.akzonobel.com, access 15.05.2018.

25. Introduction to Expancel ${ }^{\circledR}$. Bound Minerals. www. bound.com, access 15.05.2018.

26. Chemical foaming agents, Hydrocerol® basics. www.clariant.com, access 15.05.2018.

27. Weber H., De Grave I., Röhrl E., Altstädt V.: Foamed plastics. Ullmann's Encyclopedia of Industrial Chemistry. Willey VCH. 2016.

28. Sadik T., Pillon C., Carrot C., Reglero Ruiz J.: Dsc studies on the decomposition of chemical blowing agents based on citric acid and sodium bicarbonate. Thermochimica Acta, 659, 2018, 74-81.

29. Wyrzykowski D., Hebanowska E., Nowak-Wiczk G., Makowski M., Chmurzyński L.: Thermal behaviour of citric acid and isomeric aconitic acids. Journal of Thermal Analysis and Calorimetry, 2(104), 2011, 731-735.

30. ASTM F1980-07 (2011). Standard Guide for Accelerated Aging of Sterile Barrier Systems for Medical Devices. 